\title{
Optical, Photophysical, Stability and Mirrorless Lasing Properties of Novel Fluorescein Derivative Dye in Solution
}

\author{
Maram T. H. Abou-Kana \\ National Institute of Laser Enhanced Sciences, Cairo University, Giza, Egypt \\ Email: mabou202@niles.edu.eg
}

Received August 24, 2012; revised September 25, 2012; accepted October 5, 2012

\begin{abstract}
Novel laser dye, allyl 2-(6-(allyloxy)-3-oxo-3H-xanthen-9-yl) benzoate [diallyl-fluorescein] has been synthesized. Its chemical structure was confirmed by ${ }^{1} \mathrm{HNMR}$, IR, MS and elemental analysis. Its optical properties were experimentally investigated. The amplified spontaneous emission (ASE) efficiency was $0.29 \%$ in case of new dye while it was $0.23 \%$ in case of fluorescein by pumping the dye samples with a $532 \mathrm{~nm}(7 \mathrm{~ns})$ pulsed Nd:YAG laser. Also, the thermal and photostability techniques confirmed the higher stability of new laser dye.
\end{abstract}

Keywords: Laser Dye; Optical Properties; Amplified Spontaneous Emission; Thermal Stability; Photostability Property

\section{Introduction}

Dye lasers are the most versatile class of lasers with diverse applications in many scientific, industrial, medical and military applications, ranging from spectroscopy to potential counter measure devices. There is a growing devote concerning of dye laser and the search for particular laser dyes that provide high laser damage threshold and high photostability. The photophysical and lasing properties of laser dyes in liquid solutions show a strong dependence on the molecular structure of the dye [1-5]. Moreover, adequate substituent in the molecular core can alter both electronic absorption and emission maximum due to change in mobility of electrons by the nature of the substituent group in the parent dye [6-11]. This structure modification may give rise to large changes in the photophysical and optical properties [12-24]. For example displacing the emission band to longer wavelengths can be achieved by: 1) attaching electron-donating group to the dye core [25];2) rigidifying the structure [26-28]; or 3) extending the conjugation of the chromophore [29-31]. So, lasing properties should be redetermined.

Depending upon these results and trying to find novel laser dye with high laser performance and photostability, we carried out our previous work [32,33] and are now dealing with new fluorescein derivative. The present investigation deals with synthesis, chemical structure confirmation by spectroscopic techniques, photophysical properties, optical properties, stability and amplified spontaneous emission efficiency were determined and compared with the parent fluorescein itself.

\section{Experimental}

\subsection{Materials}

Fluorescein purchased from Aldrich chemical company (England) has been used without further purification, allyl bromide, potassium hydroxide, Dimethyl formamide and conc. Sulphuric acid was purchased from Aldrich and used without further purification. Solvents for photophysical and laser studies were of spectroscopic grade (Merck, Aldrich or Sigma) and were used without purification.

\subsection{Synthesis}

Preparation of the new compound allyl 2-(6-(allyloxy)-3oxo-3H-xanthen-9-yl) benzoate [diallyl-fluorescein] 2 was as follows: Fluorescein $1(1 \mathrm{mmol})$ was dissolved in hot ethanolic $\mathrm{KOH}$ solution (prepared by dissolving $(2 \mathrm{mmol})$ of $\mathrm{KOH}$ in $10 \mathrm{ml}$ of absolute ethanol), and the solvent was then removed in vacuo. The remaining material was dissolved in dimethyl formamide (DMF) $(10 \mathrm{ml})$ and allyl chloride $(2.2 \mathrm{mmol})$ was added. The reaction mixture was heated under reflux for $10 \mathrm{~min}$ with continuous stirring. The solid obtained upon cooling and dilution with water was collected and purified by crystallization from methanol solution to give orange crystals, m.p. $148^{\circ} \mathrm{C}-151^{\circ} \mathrm{C}$. The schematic reaction of the preparation of new dye is shown in Scheme 1.

\subsection{Measurements}

1) The structure of the prepared new fluorescein laser 


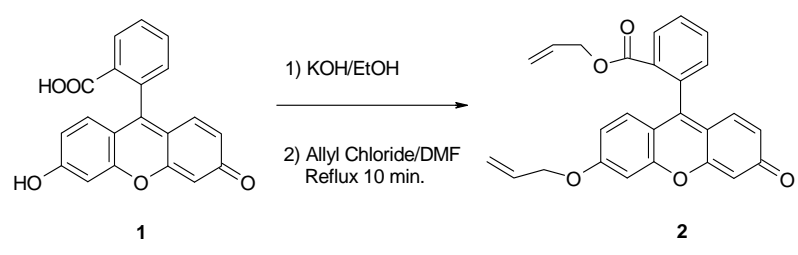

Scheme 1. The schematic reaction of the preparation of new dye.

dye derivative was confirmed by Perkin-Elmer CHN 240 B. Column chromatography: Basic alumina [activity B II-III (Brock-mann) ICN Biomedical for elemental analysis. ${ }^{1} \mathrm{HNMR}$ was recorded with a Bruker NMR spectrometer WM 300 in $\mathrm{CDCl} 3$ with tetramethylsilane as internal standard. Mass spectra (MS) were obtained with a Varian 311A instrument using Electron Impact (EI) technique.

2) Thermal stability of diallyl fluorescein and fluorescein parent were measured under atmospheric nitrogen using Shimadzu TGA-50H. Liquid solutions of the dye in different solvents were contained in 1-cm optical path quartz cells carefully sealed to avoid solvent evaporation during the experiments. Absorption and excitation-emission spectra were measured by Camspec M501 uv-vis spectrophotometer and PF-6300 spectrofluorometer respectively.

3) Optimum concentration of the dye as linear fluorescence in ethanol was detected from its absorption and emission spectra.

4) Some important photo-physical parameters of the new di-allyl fluorescein dye were determined from its absorption and excitation-emission spectra. Fluorescence quantum yields were measured by using the optically very diluted solution $\left(2 \times 10^{-6} \mathrm{M}\right)$ relative method [34,35] with solution of fluorescein as reference in $0.1 \mathrm{M} \mathrm{NaOH}$ $\left(\varphi_{f}=0.79\right)$ [36].

5) The fluorescence lifetime $(\tau f)$, were measured by using nitrogen laser (laser photonics LN1000) of pulse duration of $800 \mathrm{ps}$ and wavelength $337.1 \mathrm{~nm}$. The maximum energy per pulse was $2 \mathrm{~mJ}$. The fluorescence signal was registrated with a fast phototube (Hamamatsu R1328U-03) through optical fiber. The fast phototube $(+\mathrm{H} . \mathrm{V})$ powered by power supply at $400 \mathrm{~V}$ and connected to the $300 \mathrm{MHz}$ eZ-digital oscilloscope (DS-1530) attached to the computer processing unit for processing the spectrum.

6) The amplified spontaneous emission (ASE) spectrum and its efficiency of $2 \times 10^{-4} \mathrm{M}$ of dye in ethanol have been measured using the experimental setup in our previous work [32]. The dye sample is pumped by 532 $\mathrm{nm}$ of second harmonic Nd-YAG laser (Continuum PL7010), 7 ns pulses at a repetition rate of $5 \mathrm{~Hz}$. The exciting light was directed towards the surface of cell sample with a combination of concave lens $(f=10 \mathrm{~cm})$ and a cylindrical lens forming a line shape of dimension $\sim 0.3 \times 10 \mathrm{~mm}$. The pump fluence was $71 \mathrm{~mJ} / \mathrm{cm}^{2}$. The pumping energy (input energy) was measured via a beam splitter (4\%) and using Gentec energy meter (Model QE50). The ASE output was focused by convex lens $(f=$ $15 \mathrm{~cm}$ ) onto the Gentec power meter head (model XLE4). The ASE spectrum was recorded using the Oplenic spectrophotometer which was connected to a computer unit for processing the spectrum.

7) Thermal stability of the diallyl-fluorescein and fluorescein itself were measured using Shimadzu TGA$50 \mathrm{H}$. Photo stabilities of fluorescein parent and its new derivative were measured using the above setup as a function of number of pulses ranged from $(0-50000)$ pulse.

\section{Results and Discussion}

The chemical structure of the diallyl fluorescein dye was confirmed by ${ }^{1} \mathrm{HNMR}$, IR, mass spectroscopy as well as elemental analysis. ${ }^{1} \mathrm{HNMR}$ spectra shows that, (DMSO) $\delta=4.45-4.67\left(\mathrm{~m}, 4 \mathrm{H}, \mathrm{OCH}_{2}\right), 5.08-6.12(\mathrm{~m}, 6 \mathrm{H}$, $\left.\mathrm{CH}=\mathrm{CH}_{2}\right), 6.53-8.29(\mathrm{~m}, 10 \mathrm{H}$, ArH's $)$ ppm. While FT-IR spectra of diallyl fluorescein shows that, the absence of strong absorption bands characteristic for the phenolic $\mathrm{OH}$ as well as the carboxylic acid $\mathrm{OH}$ at $3200-$ 3500 and $2500-3400 \mathrm{~cm}^{-1}$, respectively. The IR spectrum revealed also strong absorption bands due to $\mathrm{C}=\mathrm{C}$ stretching vibration mode at $1641 \mathrm{~cm}^{-1}$ of vinyl group; and $\mathrm{C}=\mathrm{C}$ stretching at $1596 \mathrm{~cm}^{-1}$ of phenyl group. Also the structure of the new laser dye 2 was confirmed by the presence of the correct molecular ion peak at the mass spectrum; ms: $m / z(\%) 412\left(\mathrm{M}^{+}\right)$. On the other hand, elemental analysis was: Anal. Calcd. for $\mathrm{C}_{26} \mathrm{H}_{20} \mathrm{O}_{5}: \mathrm{C}$, 75.72; H, 4.89. Found: C, 75.60; H, 4.50.

Thermal stability also measured and represented in Figure 1. It shows that the fluorescein started decomposing at $200^{\circ} \mathrm{C}$ and its weight losing was $88.76 \%$ up to the temperature studied $\left(1000^{\circ} \mathrm{C}\right)$ while diallyl fluorescein started decomposing at $220^{\circ} \mathrm{C}$ and its weight losing was $77.47 \%$ up to the temperature studied $\left(1000^{\circ} \mathrm{C}\right)$.

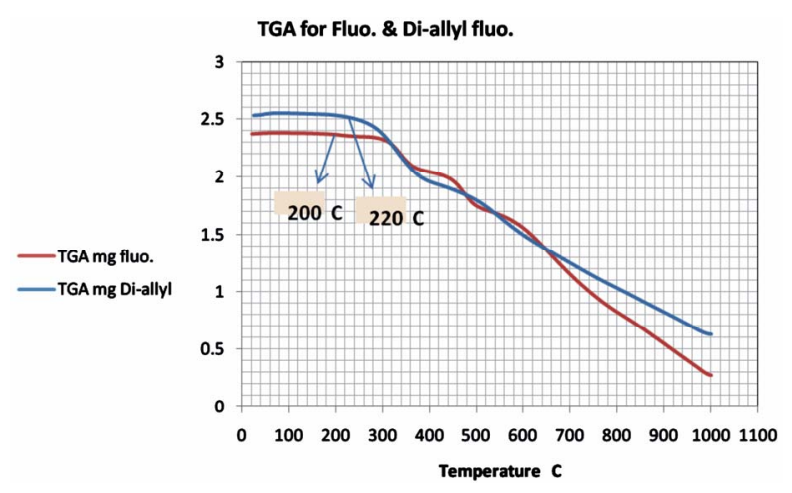

Figure 1. TGA of fluorescein and diallyl fluorescein. 
Absorption and emission spectra (shown in Figures 2 and 3 respectively) of the different concentrations of the new dye in ethanol show optimum concentration $(2 \times$ $10^{-4} \mathrm{M}$ ) at which maximum linear fluorescence was detected by exciting the sample dye with $420 \mathrm{~nm}$ wavelength, while absorption profile was changed at concentrations higher than that optimum concentration. Also, emission intensity decrease at concentrations higher than optimum concentration (shown in Figure 4) which may attributed to inner filter effect or/and the formation of its dimer form. In case of fluorescein dye, its dimer form at concentration higher than $10^{-5} \mathrm{M}$ [37].

Photophysical properties of diallyl-fluorescein in different media polarities:

The electronic absorption and emission spectra of $2 \times$ $10^{-4} \mathrm{M}$ (Figure 5) was measured at room temperature in different solvents of different polarities $[\Delta f]$ with $f$ given by the relation [38].

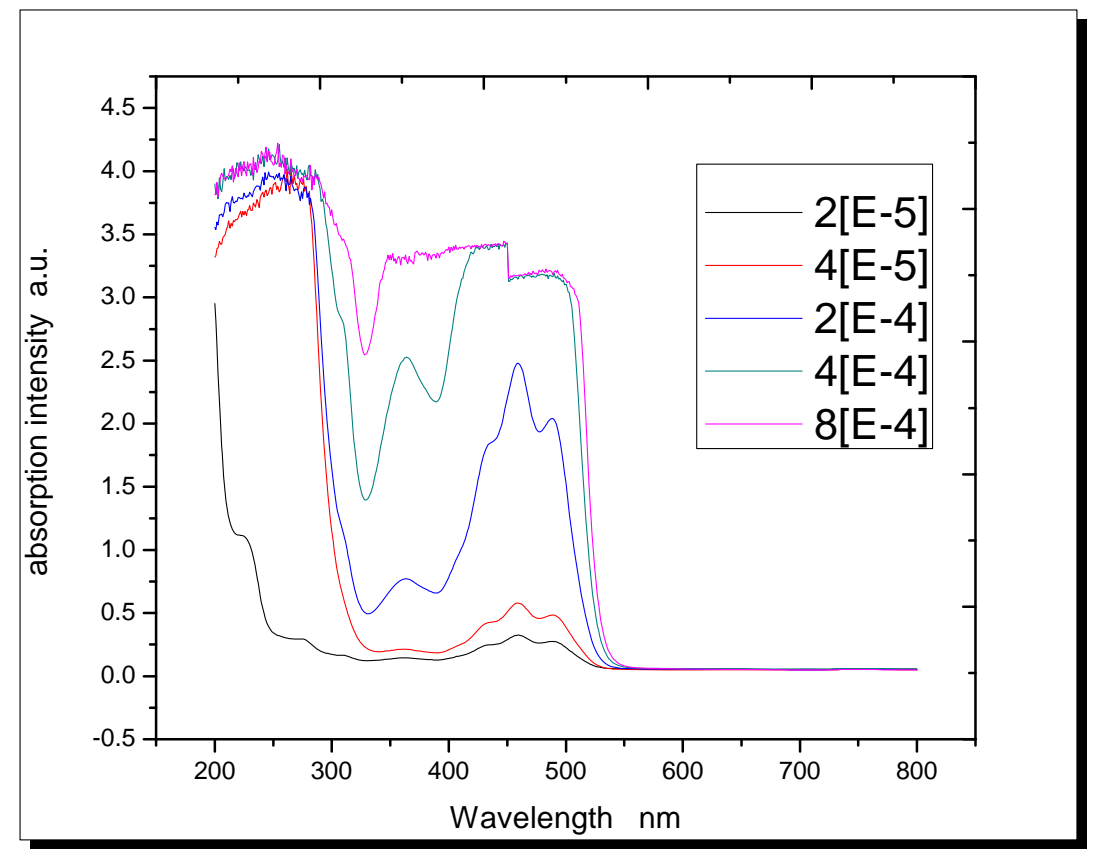

Figure 2. Absorption spectra of different concentrations of diallyl fluorescein dye in ethano.

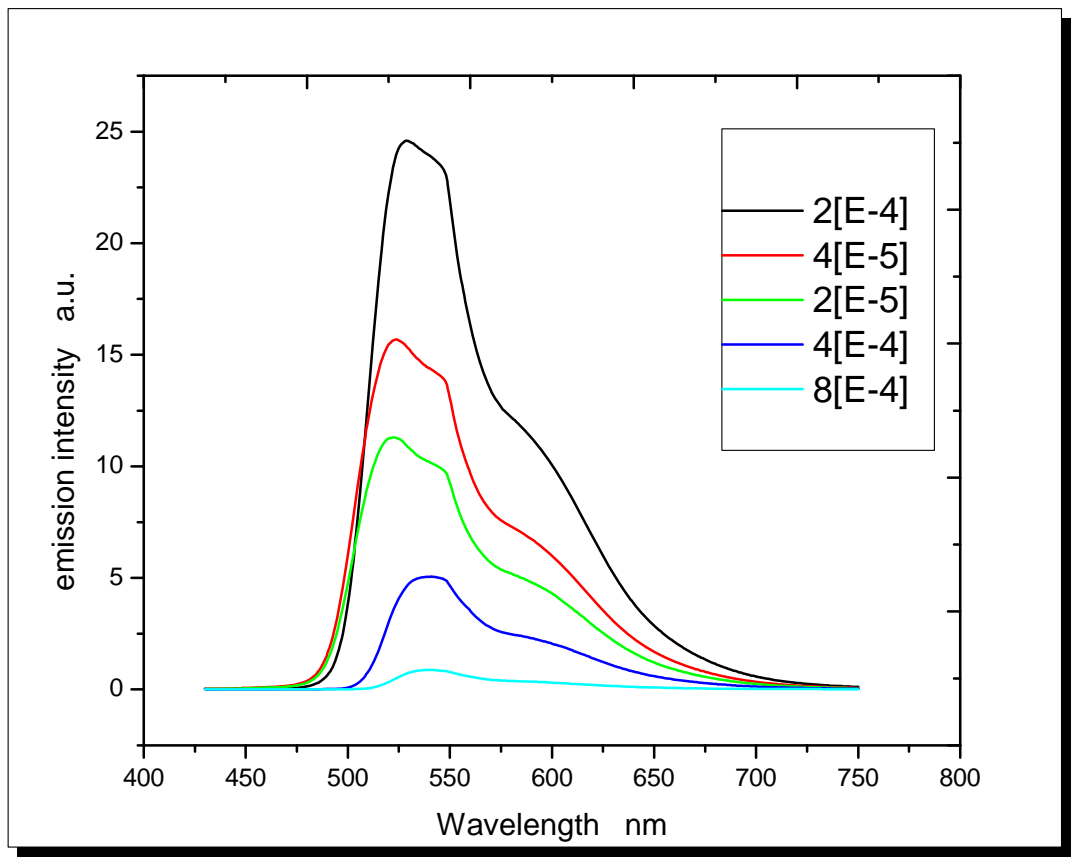

Figure 3. Emission spectra of different concentrations of diallyl fluorescein dye in ethanol. 


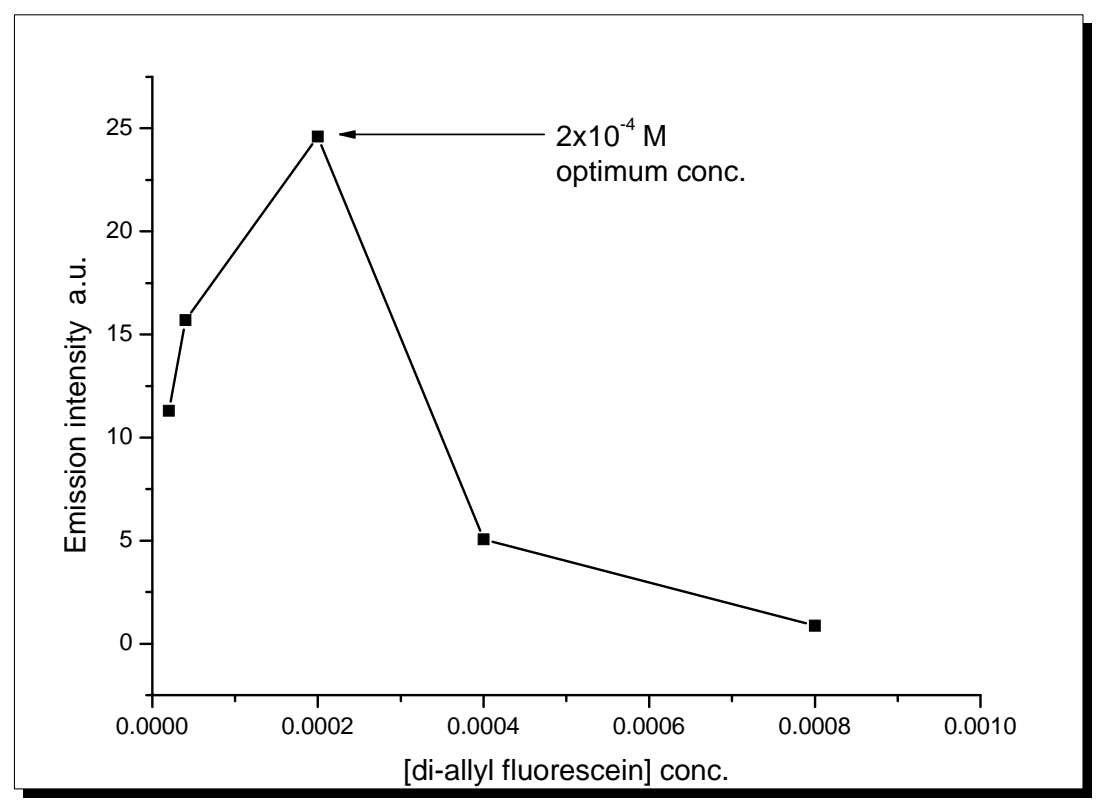

Figure 4. Emission intensity as a function of different dye concentrations in ethanol.

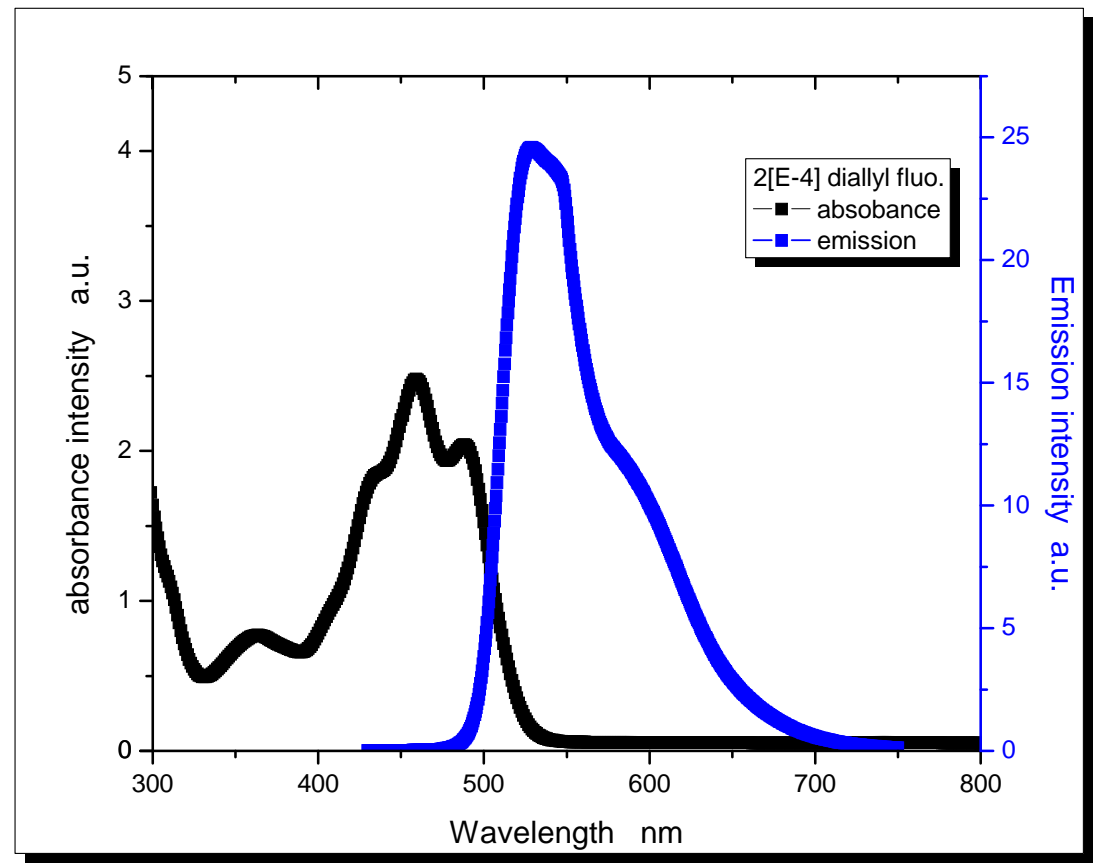

Figure 5. Absorption and emission spectra of $2 \times 10^{-4} \mathrm{M}$ diallyl fluorescein in ethanol.

$$
\Delta f=\frac{(\varepsilon-1)}{(2 \varepsilon+1)}-\frac{\left(n^{2}-1\right)}{\left(4 n^{2}+2\right)}
$$

where $(\varepsilon)$ is the dielectric constant and $(n)$ is the refractive index of the solvent. Table 1 summarizes some spectral data of diallyl-fluorescein dye in different solvents.

The absorption of dye is not strongly affected by solvent polarity, whereas the small shifts in the position of absorption spectra indicate a little change in dipole moment of dye on going from ground state to excited state. The emission spectra are significantly influenced by the medium. With increasing solvent polarity, the fluorescence maximum shifts to longer wavelengths from 497 $\mathrm{nm}$ in hexane $[\Delta f=0.091751]$ to $528.5 \mathrm{~nm}$ in ethanol $[\Delta f=$ 0.41584].

Absorption cross-section $\sigma_{a}$ and the emission crosssections $\sigma_{e}$ were calculated in ethanol solution according to the equations: $[39,40]$. 


$$
\begin{aligned}
& \sigma_{a}=0.385 \times 10^{-20} \varepsilon \\
& \sigma_{e}=\lambda_{e}^{4} E(\lambda) \varphi_{f} / 8 \pi c n^{2} \tau_{f}
\end{aligned}
$$

where: $\varepsilon$ is the molar extinction coefficient; $\lambda_{e}$ is the emission wavelength; $n$ is the refractive index of the solvent; $c$ is the velocity of light; $\phi_{f}$ is the fluorescence quantum yield; $\tau_{f}$ is the fluorescence life time; $E(\lambda)$ is the normalized fluorescence spectrum since $\int E(\lambda) \mathrm{d} \lambda=1$. Also, fluorescence quantum yield " $\varphi_{f}$ " and fluorescence life time $\tau_{f}$ of fluorescein and diallyl fluo in ethanol were determined and summarized in Table 2.

To examine the validity of the prepared new dye for lasing action, we measured the ASE efficiency (defined as the ratio of the energy of the dye laser output to the energy of the pump laser incident on the dye sample). The ASE as a function of wavelength was observed for $2 \times$ $10^{-4} \mathrm{M}$ diallyl fluorescein dye in ethanol as shown in Figure 6. The measured ASE energy versus the input pump energies are shown in Figure 7 where the threshold energy was $\sim 4 \mathrm{~mJ}$. The average ASE efficiency extracted from this input-output energy measurements were $0.29 \%$ in case of diallyl fluorescein while it was

\section{$0.23 \%$ in case of fluorescein}

To study the photostability of fluorescein parent and its new derivative, the fluorescence intensity was monitored as a function of the number of pump pulses at repetition rate $5 \mathrm{~Hz}$, pumped energy $8 \mathrm{~mJ} /$ pulse. It was found that, the fluorescence intensity decreased to nearly $42 \%$ in case of fluorescein while in case of its new derivative, it decreased to nearly $46 \%$ as shown in Figure 8.

Table 1. Photophysical parameters of dye in different sol-

\begin{tabular}{|c|c|c|c|c|}
\hline \multirow{2}{*}{ Solvent } & \multirow{2}{*}[\Deltaf]{} & \multicolumn{2}{|c|}{$\lambda_{\max }$} & \multirow{2}{*}{$\varphi_{f}$} \\
\hline & & abs. & emi. & \\
\hline Ethanol & 0.41584 & 459 & 528.5 & 0.58 \\
\hline DMF & 0.377111 & 457 & 523 & 0.60 \\
\hline Acetone & 0.374482 & 457 & 522 & 0.53 \\
\hline DMSO & 0.373593 & 456 & 518 & 0.71 \\
\hline Iso-propanol & 0.36977 & 455 & 510 & 0.79 \\
\hline THF & 0.30838 & 456 & 507.5 & 0.54 \\
\hline 1,4-Dioxane & 0.125892 & 455 & 502.5 & 0.66 \\
\hline Hexane & 0.091751 & 454 & 497 & 0.52 \\
\hline
\end{tabular}
vent polarity.

Table 2. Maximum wavelength of absorption " $\lambda_{a b(\max )}$ " and emission " $\lambda_{e m(\max )}$ "; molecular extinction coefficient “ $\varepsilon$ "; cross-sections of absorption " $\sigma a$ ", and emission " $\sigma e$ "; fluorescence quantum yield " $\varphi_{f}$ " and fluorescence life time $\tau_{f}$ of fluorescein and diallyl fluo in ethanol.

\begin{tabular}{cccccccc}
\hline Dye in ethanol & $\lambda_{a b(\max )}$ & $\lambda_{e m(\max )}$ & $\varepsilon) \mathrm{L} \cdot \mathrm{M}^{-1} \cdot \mathrm{cm}^{-1}\left(10^{3}\right)$ & $\sigma_{a}\left(10^{-17}\right) \mathrm{cm}^{2}$ & $\sigma_{e}\left(10^{-16}\right) \mathrm{cm}^{2}$ & $\phi_{f}$ & $\tau_{f}(\mathrm{~ns})$ \\
\hline Fluorescein & 449 & 518.5 & 4.2 & 1.62 & 2.78 & 0.51 & 6.8 \\
Diallyl fluorescein & 459 & 528.5 & 12.399 & 4.77 & 3.90 & 0.58 & 6.2 \\
\hline
\end{tabular}

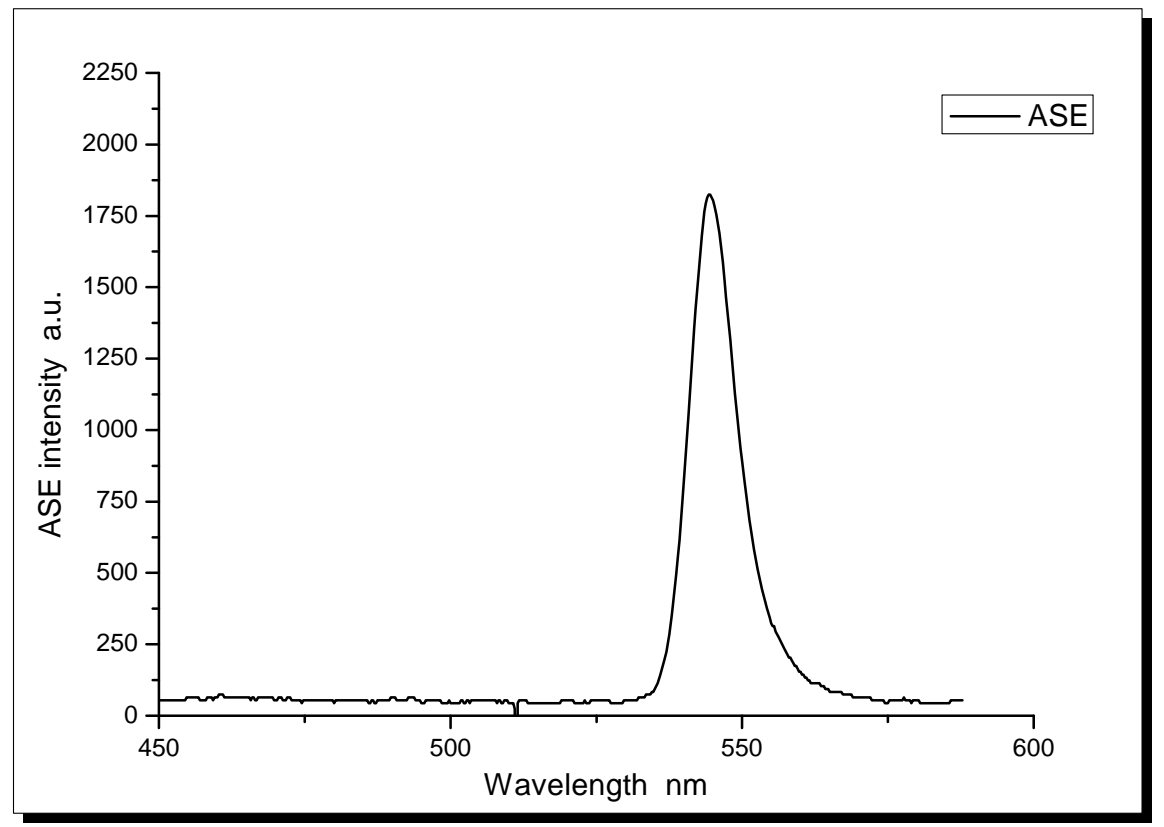

Figure 6. ASE of $2 \times 10^{-4} \mathrm{M}$ of diallyl fluorescein in ethanol. 


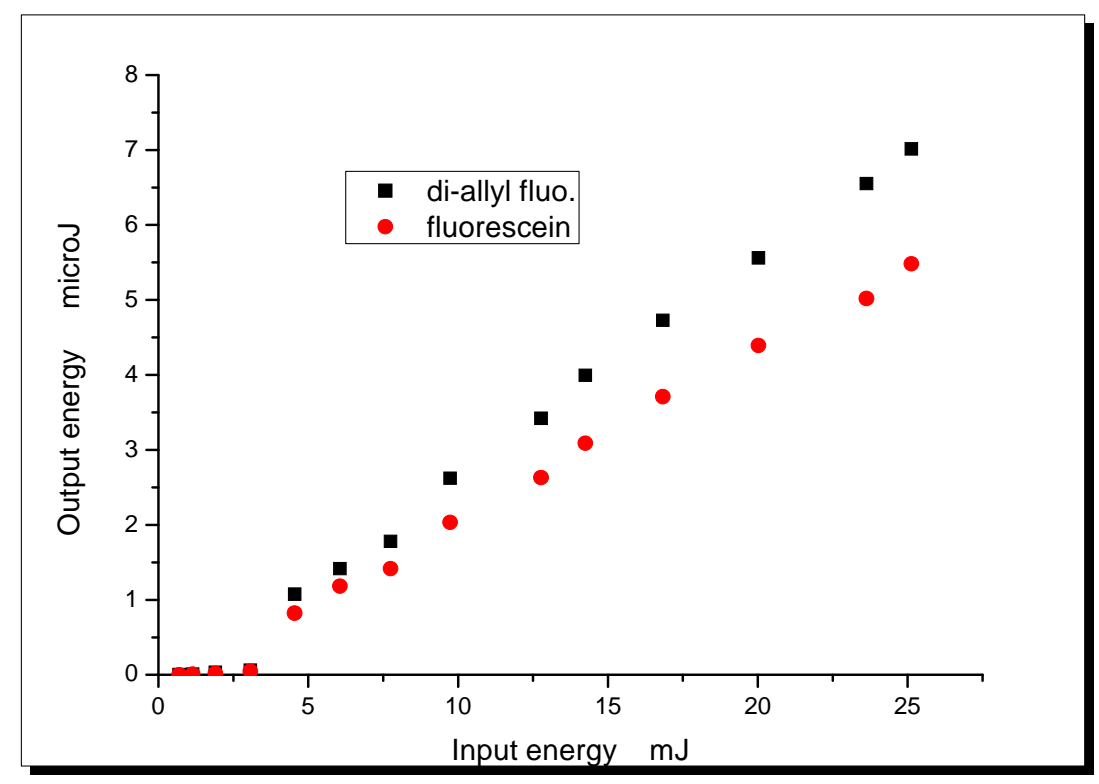

Figure 7. ASE efficiency of diallyl fluorescein and fluorescein in ethanol.

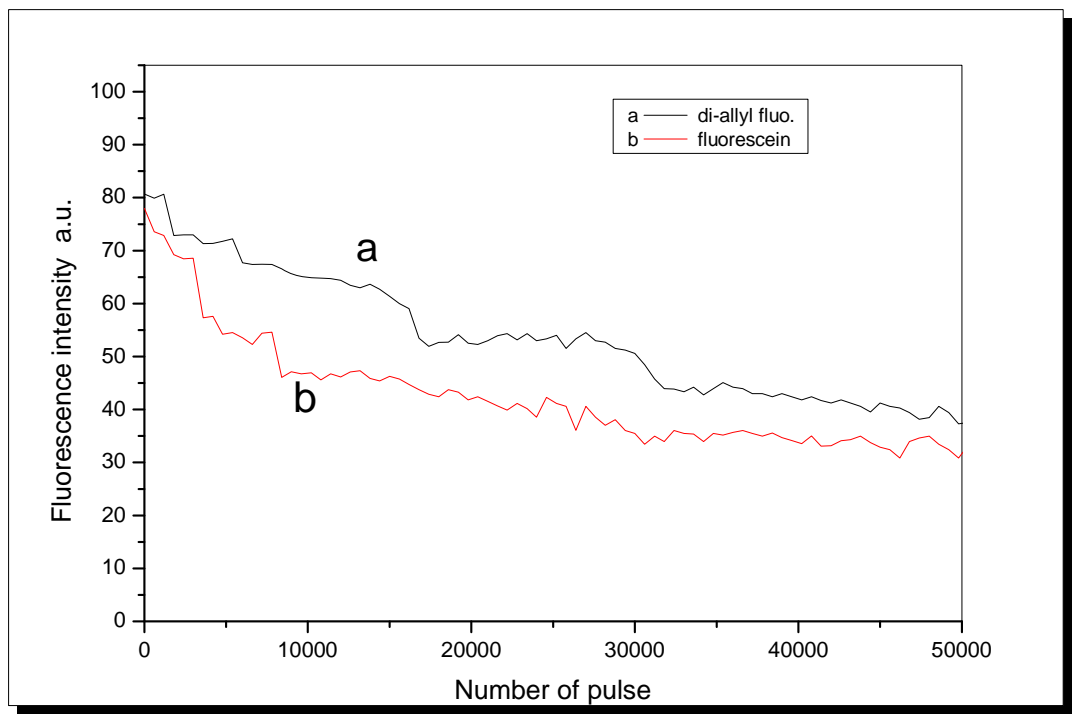

Figure 8. Fluorescence intensity as a function of the number of pumping pulses at repetition rate $5 \mathrm{~Hz}$ and pumping power 8 $\mathrm{mJ}$ of $532 \mathrm{~nm}$ Nd-YAG laser.

\section{Conclusion}

In this work, we reported efficient laser operation from novel synthesized diallyl derivative of fluorescein. Electronic absorption, emission and fluorescence quantum yield in different solvents were measured. The solvent polarity and viscosity have great effect on tunability properties of new dye. Absorption cross section, emission cross section and fluorescence lifetime of the new dye were investigated and compared with that of fluorescein itself. Under the same experimental condition, the ASE efficiency was $0.29 \%$ in case of new dye while it was $0.23 \%$ in case of fluorescein dye with threshold energy of the order of about $4 \mathrm{~mJ}$. Also, thermal stability and photostability measurements confirmed the higher stability of new fluorescein derivative returns.

\section{REFERENCES}

[1] M. A. lvarez, F. Amat-Guerri, A. Costela, I. Garcia-Moreno, M. Liras and R. Sastre, "Laser Emission from Mixtures of Dipyrromethene Dyes in Liquid Solution and in Solid Polymeric Matrices," Optics Communications, Vol. 267, No. 2, 2006, pp. 469-479. doi:10.1016/j.optcom.2006.06.059

[2] J. Ringling, O. Kittelmann, F. Noack, U. Stamm, J. Kleinschmidt and F. Voss, "High-Repetition-Rate High-Power 
Femtosecond ArF Laser Source," Optics Letters, Vol. 19, No. 20, 1994, pp. 1639-1641. doi:10.1364/OL.19.001639

[3] F. L. Arbeloa, T. L. Arbeloa, I. L. Arbeloa, I. García-Moreno, A. Costela, R. Sastre and F. Amat-Guerri, "Correlations between Photophysics and Lasing Properties of Dipyrromethene- $\mathrm{BF}_{2}$ Dyes in Solution," Chemical Physics Letters, Vol. 299, No. 3-4, 1999, pp. 315-321. doi:10.1016/S0009-2614(98)01281-0

[4] J. H. Boyer, A. Haag, M.-L. Soong, K. Thangaraj and T. G. Pavlopoulos, "First-Order Sources in First-Order Systems: Second-Order Correlations: Errata," Applied Optics, Vol. 30, No. 27, 1991, p. 3788. doi:10.1364/AO.30.003788

[5] J. H. Boyer, A. Haag, G. Sathyamoorthi, M.-L. Soong, K. Thangaraj and T. G. Pavlopoulos, "Pyrromethene- $-\mathrm{BF}_{2}$ Complexes as Laser Dyes," Heteroatom Chemistry, Vol. 4, 1993, pp. 39-49. doi:10.1002/hc.520040107

[6] S. A. Azim, S. M. Al-Hazmy, E. M. Ebeid and S. A. El-Daly, "A New Coumarin Laser Dye 3-(benzothiazol2-yl)-7-hydroxycoumarin," Optics \& Laser Technology, Vol. 37, No. 3, 2005, pp. 245-249. doi:10.1016/j.optlastec.2004.04.003

[7] M. R. Padlye, T. S. Varadarian and A. V. Deshande, "Some New Laser Dyes-Solvent Effect on QE and Lasing Action," Spectroscopy Letters: An International Journal for Rapid Communication, Vol. 15, No. 8, 1982, pp. 597-608. doi:10.1080/00387018208068016

[8] V. Masilamani and B. M. Sivaram, "The Laser Gain Characteristics of Some Substituted Coumarins," Journal of Luminescence, Vol. 27, No. 2, 1982, pp. 137-145. doi:10.1016/0022-2313(82)90015-1

[9] R. Giri, S. S. Rathi, M. K. Machwe and V. S. Murti, "Effect of Substituents on the Fluorescence and Absorption Spectra of Coumarins," Spectrochimica Acta Part A: Molecular Spectroscopy, Vol. 44, No. 8, 1988, pp. 805-807. doi:10.1016/0584-8539(88)80146-6

[10] A. Ramalingam, P. K. Palanisomy, V. Masilamani and B. M. Sivaram, "Dual Amplified Spontaneous Emission from 7-amino-4-methyl Coumarin Dye," Journal of Photochemistry and Photobiology A: Chemistry, Vol. 49, No. 1-2, 1989, pp. 89-96.

doi:10.1016/1010-6030(89) 87108-4

[11] S. A. Al-Hazmy, K. N. Kassab, S. A. El-Daly and E. M. Ebeid, "Spectral Properties of (5-Phenyl-1,3,4-Oxadiazol2-yl)-7-Hydroxycoumarin (POHC)," Spectrochimica Acta Part A: Molecular and Biomolecular Spectroscopy, Vol. 56, No. 9, 2000, pp. 1773-1780. doi:10.1016/S1386-1425(00)00231-6

[12] A. Costela, I. García-Moreno, M. Pintado-Sierra, F. AmatGuerri, M. Liras, R. Sastre, F. L. Arbeloa, J. B. Prieto and I. L. Arbeloa, "New Laser Dye Based on the 3-Styryl Ana$\log$ of the BODIPY dye PM567," Journal of Photochemistry and Photobiology A: Chemistry, Vol. 198, No. 2-3, 2008, pp. 192-199. doi:10.1016/j.jphotochem.2008.03.010,

[13] R. Ziessel, C. Goze, G. Ulrich, M. Cesario, P. Retailleau, A. Harriman and J. P. Rostron, "Intramolecular Energy Transfer in Pyrene-Bodipy Molecular Dyads and Triads,"
Chemistry: A European Journal, Vol. 11, No. 24, 2005, pp. 7366-7378. doi:10.1002/chem.200500373

[14] M. Baruah, W. Quin, R. A. L. Vallee, D. Beljonne, T. Rohand, W. Dehaen and N. Boens, "A Highly PotassiumSelective Ratiometric Fluorescent Indicator Based on BODIPY Azacrown Ether Excitable with Visible Light," Organic Letters, Vol. 7, No. 20, 2005, pp. 4377-4380. doi:10.1021/o1051603o

[15] Z. Dost, S. Atildan and E. U. Akkaya, "Distyryl-BoradiAzaindacenes: Facile Synthesis of Novel near IR Emitting Fluorophores," Tetrahedron, Vol. 62, No. 36, 2006, pp. 8484-8488. doi:10.1016/j.tet.2006.06.082

[16] T. Rohand, M. Baruah, W. Quin, N. Boens and W. Dehaen, "Functionalisation of Fluorescent BODIPY Dyes by Nucleophilic Substitution," Chemical Communications, Vol. 42, No. 3, 2006, pp. 266-268. doi:10.1039/b512756d

[17] A. Coskun, E. Deniz and E. U. Akkaya, "Effective PET and ICT Switching of Boradiazaindacene Emission: A Unimolecular, Emission-Mode, Molecular Half-Subtractor with Reconfigurable Logic Gates," Organic Letters, Vol. 7, No. 23, 2005, pp. 5187-5189. doi:10.1021/01052020h

[18] N. Saki, T. Dinic and E. U. Akkaya, "Excimer Emission and Energy Transfer in Cofacial Boradiazaindacene (BODIPY) Dimers Built on a Xanthene Scaffold," Tetrahedron, Vol. 62, No. 11, 2006, pp. 2721-2725. doi:10.1016/j.tet.2005.12.021

[19] A. Costela, I. García-Moreno, C. Go'mez, F. Amat-Guerri and R. Sastre, "Efficient and Stable Dye Laser Action from Modified Dipyrromethene $\mathrm{BF}_{2}$ Complexes," Applied Physics Letters, Vol. 79. No. 3, 2001, pp. 305-307. doi:10.1063/1.1385185

[20] A. Costela, I. García-Moreno, C. Gomez, R. Sastre, F. Amat-Guerri, M. Liras, F. L. Arbeloa, J. B. Prieto and I. L. Arbeloa, "Photophysical and Lasing Properties of New Analogs of the Boron-Dipyrromethene Laser Dye PM567 in Liquid Solution," The Journal of Physical Chemistry A, Vol. 106, No. 34, 2002, pp. 7736-7742. doi:10.1021/jp0209897

[21] A. Costela, I. García-Moreno, C. Gomez, F. Amat-Guerri, M. Liras and R. Sastre, "Efficient and Highly Photostable Solid-State Dye Lasers Based on Modified Dipyrromethene $\mathrm{BF}_{2}$ Complexes Incorporated into Solid Matrices of Poly(Methyl Methacrylate)," Applied Physics B, Vol. 76, No. 4, 2003, pp. 365-369. doi:10.1007/s00340-003-1139-1

[22] F. L. Arbeloa, J. B. Prieto, I. L. Arbeloa, A. Costela, I. García-Moreno, C. Gomez, F. Amat-Guerri, M. Liras and R. Sastre, "Photophysical and Lasing Properties of New Analogs of the Boro-Dipyrromethene Laser Dye Pyrromethene 567 Incorporated into or Covalently Bounded to Solid Matrices of Poly(methyl methacrylate)," Photochemistry and Photobiology, Vol. 78, No. 1, 2003, pp. 30-36. doi:10.1562/0031-8655

[23] I. García-Moreno, A. Costela, L. Campo, R. Sastre, F. Amat-Guerri, M. Liras, F. L. Arbeloa, J. B. Prieto and I. L. Arbeloa, "8-Phenyl-Substituted Dipyrromethene $\cdot \mathrm{BF}_{2}$ Complexes as Highly Efficient and Photostable Laser Dyes, The Journal of Physical Chemistry A, Vol. 108, No. 
16, 2004, pp. 3315-3323. doi:10.1021/jp0312464

[24] M. Alvarez, F. Amat-Guerri, A. Costela, I. García-Moreno, C. Gomez, M. Liras and R. Sastre, "Linear and CrossLinked Polymeric Solid-State Dye Lasers Based on 8-Substituted Alkyl Analogues of Pyrromethene 567," Applied Physics B, Vol. 80, No. 8, 2005, pp. 993-1006. doi:10.1007/s00340-005-1833-2

[25] A. Burghart, H. Kim, M. B. Welch, L. H. Thoresen, J. Reibenspies and K. Burgess, "3,5-Diaryl-4,4-Difluoro-4Bora-3a,4a-Diaza-s-Indacene (BODIPY) Dyes: Synthesis, Spectroscopic, Electrochemical, and Structural Properties," Organic Chemistry, Vol. 64, No. 21, 1999, pp. 78137819. doi:10.1021/j0990796o

[26] J. Chen, A. Burghart, A. Derecskei-Kovacs and K. Burgess, "4,4-Difluoro-4-Bora-3a,4a-Diaza-s-Indacene (BODIPY) Dyes Modified for Extended Conjugation and Restricted Bond Rotations," The Journal of Organic Chemistry, Vol. 65, No. 10, 2000, pp. 2900-2906. doi:10.1021/j0991927o

[27] H. Kim, A. Burghart, M. B.Welch, J. Reibenspies and K. Burgess, "Synthesis and Spectroscopic Properties of a New 4-Bora-3a,4a-Diaza-s-Indacene (BODIPY ${ }^{\mathbb{R}}$ ) Dye," Chemistry Communications, Vol. 35, No. 18, 1999, pp. 18891890. doi:10.1039/a905739k

[28] J. Chen, J. Reibenspies, A. Derecskei-Kovacs and K. Burgess, "Through-Space ${ }^{13} \mathrm{C}-{ }^{19} \mathrm{~F}$ Coupling Can Reveal Conformations of Modified BODIPY Dyes," Chemistry Communications, Vol. 35, No. 24, 1999, pp. 2501-2502. doi:10.1039/a907559c

[29] K. Rurack, M. Kollmannberger and J. Daub, “A Highly Efficient Sensor Molecule Emitting in the Near Infrared (NIR): 3,5-distyryl-8-(p-dimethylaminophenyl) Difluo-roboradiaza-s-indacene," New Journal of Chemistry, Vol. 25, No. 2, 2001, pp. 289-292. doi:10.1039/b007379m

[30] K. Rurack, M. Kollmannsberger and J. Daub, "Molecular Switching in the Near Infrared (NIR) with a Functionalized Boronz-Dipyrromethene Dye," Angewandte Chemie International Edition, Vol. 40, No. 2, 2001, pp. 385387.

[31] W. Zhao and E. M. Carreira, "Conformationally Restricted Aza-Bodipy: A Highly Fluorescent, Stable, Near-Infrared Absorbing Dye," Angewandte Chemie International Edition, Vol. 44, No. 11, 2005, pp. 1677-1679. doi:10.1002/anie. 200461868
[32] H. A. S. Al-Shamiri, M. T. H. Abou Kana, I. M. Azzouz and A. H. M. Elwahy, "Photo-Physical Properties and Amplified Spontaneous Emission of a New Derivative of Fluorescein," Optics Communications, Vol. 283, No. 7, 2010, pp. 1438-1444. doi:10.1016/j.optcom.2009.12.028

[33] M. T. H. A. Kana, H. A. S. Al-Shamiri, I. M. Azzouz and A. H. M. Elwahy, "Spectroscopic Properties and Amplified Spontaneous Emission of a New Derivative of Fluorescein," Applied Physics B, Vol. 88, No. 4, 2007, pp. 575-580. doi:10.1007/s00340-007-2727-2

[34] J. V. Morris, M. A. Mahaney and J. R. Huber, "Fluorescence Quantum Yield Determinations. 9,10-Diphenylanthracene as a Reference Standard in Different Solvents," The Journal of Physical Chemistry, Vol. 80, No. 9, 1976, pp. 969-974. doi:10.1021/j100550a010

[35] J. N. Demas and G. A. Crosby, "Measurement of Photoluminescence Quantum Yields. Review," The Journal of Physical Chemistry, Vol. 75, No. 8, 1971, pp. 991-1024. doi:10.1021/j100678a001

[36] J. Q. Umberger and V. K. LaMer, "The Kinetics of Diffusion Controlled Molecular and Ionic Reactions in Solution as Determined by Measurements of the Quenching of Fluorescence," Journal of American Chemical Society, Vol. 67, No. 7, 1945, pp. 1099-1109. doi: $10.1021 / \mathrm{ja} 01223 \mathrm{a} 023$

[37] S. Speiser and F. L. Chisena, "Optical Bistability in Fluorescein Dye," Applied Physics B, Vol. 45, No. 3, 1988, pp. 137-144. doi:10.1007/BF00695282

[38] T. D. Z. Atvars, C. A. Bortolato and D. D. Bruneli, "Electronic Absorption and Fluorescence Spectra of Xanthene dyes in Polymers," Journal of Photochemistry and Photobiology A: Chemistry, Vol. 68, No. 1, 1991, pp. 41-50. doi:10.1016/1010-6030(92)85016-N

[39] B. B. Raju and T. S. Varadrajan, "Photophysical Properties and Energy Transfer Dye Laser Characteristics of 7-Diethylamino-3-Heteroaryl Coumarin in Solution," Laser Chemistry, Vol. 16, No. 2, 1995, pp. 109-120. doi:10.1155/1995/51920

[40] A. Costela, J. M. Munoz, A. Douhal, J. M. Figuera and A. V. Acune, "Experimental Test of a Four-Level Kinetic Model for Excited-State Intramolecular Proton Transfer Dye Lasers," Applied Physics B, Vol. 49, No. 6, 1989, pp. 545-552. doi:10.1007/BF00324955 